Daimon. Revista Internacional de Filosofía, $n^{\circ} 73$ (Enero-Abril) 2018, 95-105

ISSN: 1130-0507 (papel) y 1989-4651 (electrónico)

http://dx.doi.org/10.6018/daimon/249551

\title{
El universo Tagore
}

\author{
The Tagore Universe
}

CARLOS ELÍO MENDIZÁBAL*

\begin{abstract}
Resumen: Dentro de lo que constituye «el pensamiento de la India» reciente, Tagore, representa, mediante su vida y su obra, la actitud del artista y del intelectual moderno que sin renunciar nunca a sus orígenes es capaz de abrirse a nuevos horizontes. Comprometido con sus creencias y comprometido con su tierra y su tiempo, es hoy uno de los referentes para entender que el diálogo entre culturas es algo necesario.
\end{abstract}

Palabras clave: Cultura, Espiritualidad, Oriente, Pensamiento, Poesía.

\begin{abstract}
Within the recent thinking from India, Tagore represents by means of his life and his work, the attitude of the modern artist and intellectual, who is able to open to new horizons without denying his origins. Devoted to his beliefs and devoted to his homeland and his time, he constitutes today one of the guides to understand that the dialogue between cultures is something necessary.
\end{abstract}

Keywords: Culture, Spirituality, West, Thinking, Poetry.

Cuando se pretende abordar la figura de Tagore surge el dilema de, o bien optar por referirse exclusivamente a una de sus dimensiones: poeta, pensador, educador, músico, pintor..., o bien tratar los diferentes registros de su obra llevando a cabo una labor integradora de los mismos bajo un denominador común. En cualquiera de los casos se nos plantean los inconvenientes que conlleva escribir sobre un autor tan polifacético y con una obra tan extensa ${ }^{1}$. En el primer supuesto, al referirnos exclusivamente a una faceta, se sacrifican las restantes facetas presentes en el autor, por lo cual elaboramos una imagen incompleta; en el segundo caso, al tratar de abarcar la totalidad de su obra, se plantea el problema de la imposibilidad de profundizar, mediante un texto de extensión limitada, en los diferentes campos en que se desarrolla la misma.

Recibido: 03/02/2016. Aceptado: 30/05/2016.

* $\quad$ Profesor de Filosofía en el Colegio Maristas de Palencia. Licenciado en Derecho por la Universidad de Valladolid y Máster en Filosofía Teórica y Práctica en la especialidad Historia de la Filosofía y del Pensamiento Contemporáneo UNED. Doctorando en Filosofía. Principal línea de investigación: Relaciones entre filosofía y literatura. Último trabajo publicado «La penumbra salvadora» en Daimon - Revista Internacional de Filosofía, 66 (2015).carloseliovalladolid@hotmail.com

1 Como señala Uma das Gupta en su introducción a la selección de los textos autobiográficos recogidos en el libro «Palabra por palabra» «Es interesante observar que Rabindranath fue un escritor extraordinariamente prolífico, y que el material que nos ha dejado tras su vida inusualmente activa es inacabable. En Bengala hay un dicho que afirma que es imposible leer en toda una vida lo que Rabindranath escribió en su vida». 
Hemos optado por una vía media, buscando por una parte ofrecer lo que entendemos forma el núcleo fuerte de su pensamiento, «el fondo insobornable» de su vida y de su obra: su profunda espiritualidad. Y por otra parte referirnos a algunos aspectos centrales de su quehacer creativo que, partiendo de esta seña de identidad, se diversifican en plurales formas expresivas. Teniendo en cuenta que Tagore no distinguió entre su vida y su obra, y que ambas están interrelacionadas de tal manera que no es posible entender la una sin la otra, es preciso asumir, por lo tanto, la existencia de una unidad subterránea en toda su producción.

Tagore representa muy bien una tradición cultural que es la suya, pero al mismo tiempo enriquecida con la aceptación de otras culturas. Si por algo se caracteriza Tagore es por su talante conciliador, tolerante, nada dogmático, abierto a la modernidad pero sabiendo muy bien cuales son sus raíces.

El título del presente texto «El universo Tagore» ya nos indica que estamos en presencia de una obra de «totalidad». Universo en cuanto que comprende aspectos muy diversos aunque siempre tratados desde una misma óptica profundamente humanista.

En Occidente existe una imagen de Tagore muy parcial e imprecisa con gran desconocimiento de ciertas facetas de su obra. La imagen, un tanto delicuescente, que se nos ha transmitido es la de un poeta de un vago lirismo exótico que poco tiene que ver con la estatura artística y moral del escritor indio.

\section{La liberación interior}

Pese a sus contactos con Occidente, Tagore, siempre tuvo muy presente cuales eran sus raíces y profesó con convicción profunda unas ideas y creencias que entroncan con la tradición de su país. Para comprender mejor a Tagore es preciso referirse a la influencia que ejerció sobre él su padre. El padre de Rabindranath siguió un camino propio, apartándose del mundo de los negocios y convirtiéndose en un líder espiritual. Debendranath, que así se llamaba el padre de Rabindranath, fue el continuador de Ram Mohan Roy, llamado a veces «el padre de la India moderna», un brahmana bengalí que fundó el Brahmo Samaj («la sociedad del brahmán»), primer movimiento hinduista de reforma. «El Brahmo Samaj defendía unas ideas que consideraba la esencia común de todas las religiones, una especie de deísmo racionalista y ético que Roy creía encontrar en las upanisad y que sería lo sustancial de un hinduismo originario purificado de supersticiones épicopuránicas»².

Se trataba, pues, de purificar el hinduismo de la idolatría y de las supersticiones y de establecer el culto de un Dios trascendente y neutro, más allá de todas las formas, un Dios sin un único nombre que es fundamento de todas las religiones. Aunque la inspiración era claramente occidental, Roy, trató de encontrar en el mismo hinduismo las bases de este credo reformado. Como señala $\mathrm{M}^{\mathrm{a}}$ Teresa Román López, «Para Roy, el «alma» del pensamiento indio lo constituían fragmentos escogidos del Vedânta, la literatura piadosa y la Bhagavadgîtâ («El Canto del Señor»). Asimismo encontró en el núcleo de la filosofía Vedânta, tal como se exponen en las Upanishads, un principio de razón» ${ }^{3}$.

2 Ruiz Calderón, Javier (2008), Breve historia del hinduismo, Madrid: Biblioteca Nueva, p. 203.

3 Román López, María Teresa (2001), Enseñanzas espirituales de la India, Madrid: Oberón, p. 59. 
Debendrenath, padre de Rabindranath, confirió al Samaj una impronta más hinduista, consiguiendo de esta forma mayor número de adeptos. Con el tiempo este movimiento reformista derivó hacia una especie de religiosidad universal que trató de integrar las visiones de Oriente y Occidente. Su mayor mérito consistió en tratar de aproximar el hinduismo a la modernidad.

Rabindranath Tagore, como él mismo reconoció, muy influenciado por el Samaj, las Upanishads, el vaisnaismo devocional, la educación occidental y el cristianismo; evolucionó hacia una concepción de la vida profundamente tolerante y humanitaria, hacia una mística que parte de una vivencia religiosa personal de un Dios inmanente en el mundo, con quien el alma aspira a fundirse. «Entre quienes se esfuerzan por conocer al Absoluto, los hay que alcanzan un conocimiento integral del Divino, a un tiempo trascendente e inmanente. Según el Upanishad, participan con el Supremo en el juego de la Creación y, al incluir en su existencia la actividad en todas sus formas, toman conciencia de la exultación universal. Para ellos, Dios es el Omnipresente que anima todo cuanto existe» ${ }^{4}$.

El magisterio espiritual del padre siempre estuvo presente en Tagore que en su obra autobiográfica recuerda «Había algo curioso en nuestra familia. Era como si viviésemos cercanos a la era de la India pre-puránica a través de nuestro compromiso con las Upanishads. De niño me crié recitando slokas de las Upanishads con clara enunciación.

No teníamos experiencia alguna de los excesos emocionales que prevalecían en la vida religiosa de Bengala. La vida espiritual de mi padre era tranquila y controlada ${ }^{5}$.

Esta vida espiritual tranquila y controlada también va a prevalecer en Rabindranath Tagore. Su vida y su obra que, como ya hemos dicho anteriormente, no pueden disociarse, constituyen una búsqueda permanente de la «liberación interior». En este camino Tagore se muestra integrador, frente a las concepciones dualistas proclama la necesidad de armonización de los contrarios, frente a la fatalidad y al ritualismo supersticioso proclama la acción, la liberación a través del conocimiento.

En este sentido podemos decir que, pese a su personalidad independiente, la influencia del Vedânta ${ }^{6}$, es patente en Tagore, y dentro de este sistema doctrinal ortodoxo, Tagore participa, en cierta manera, de la visión mantenida por la escuela advaita o monismo absoluto. «Sólo me cabe inclinarme con veneración ante el monista que, al escapar -siquiera por un instante- de nuestra percepción engañosa del tiempo, se sumerge íntegramente en las profundidades inmaculadas e inviolables de una eterna complitud en el seno del Absoluto, en un océano de éxtasis donde reinan un silencio y una paz inmutables. En modo alguno me siento inclinado a atacar su visión fundamental de Dios y de la Creación» ${ }^{7}$.

4 Tagore, Rabindranath (1999), La morada de la paz, Barcelona: Ediciones Oniro, p. 205.

5 Tagore, Rabindranath (2010), Palabra por palabra (Textos autobiográficos), Barcelona: La otra orilla, p. 22.

6 Dentro de los sistemas doctrinales ortodoxos o propiamente hindúes es preciso situar el Vedânta, «Los sistemas astika u ortodoxos son ante todo denominados así porque reconocen y afirman la autoridad de los vedas como libros sagrados fuentes de la revelación. También se denominan así porque afirman la existencia de un âtman, de una sustancia, de un sujeto y por tanto de una supervivencia después de la existencia temporal; son pues sistemas «creyentes», aunque la creencia en una vida transtemporal sea interpretada de las formas más variadas. Otra acepción de astika, como su nombre indica, es la filosofía del ser. Los sistemas ortodoxos reconocen, pues, la existencia de un ser, de un Dios en una forma u otra absoluto, distinto y por encima del universo». (Román López, ob. cit., 234).

7 Tagore, R. La morada de la paz, pp. 221-222. 
No obstante, Tagore, discrepa del rechazo mantenido por esta escuela hacia la acción, rechazo que se deriva de una concepción, fundamentalmente, ilusionista del mundo fenoménico. Para, Tagore, la acción nos esclaviza cuando actuamos movidos por la obligación o la necesidad, pero, cuando por el contrario, es la alegría lo que nos mueve, nos libera. Así, su vida fue un ejemplo de entrega entusiasta, de búsqueda apasionada, «el objetivo supremo de la búsqueda espiritual consiste en abrirse a la propia alma, a fin de poder penetrar en el alma del universo, presente en la más imperceptible partícula de materia. La vía que adoptemos, si uno se aplica a seguirla, debe conducir a esa realización. Ahora bien, la meta no puede alcanzarse entretanto uno se deje dominar por la apatía y la ceguera. Para ampliar y desarrollar la conciencia individual, es indispensable, por una parte, reconocer la necesidad del esfuerzo, y por otra, actuar con plena lucidez. Es preciso querer progresar sin interrupción hacia una verdadera comprensión del mundo. Entonces se desvela poco a poco ante nuestros ojos el camino que conduce al ser, y nos acercamos cada vez más al núcleo de la vida» ${ }^{8}$.

La religiosidad de Tagore es una religiosidad abierta, ajena a los dogmas y a las teorías. Religiosidad panteísta en la que todo el universo es expresión divina y que encuentra su cauce mejor de transmisión a través de la poesía, a través de un lenguaje que no necesita explicarse a sí mismo.

La religión, tal y como es entendida por Tagore, constituye un tema al que dedicó especial atención, además de impregnar de una u otra forma gran parte de su extensa obra, fue objeto de un libro que precisamente lleva por título La religión del hombre ${ }^{9}$. En este libro, Tagore, nos expone su peculiar visión del fenómeno religioso y también como, desde su experiencia personal, ha evolucionado hasta llegar a una aceptación en su propia vida del hecho religioso como algo natural y que no precisa de explicaciones lógicas. Llegando a señalar que, en su caso, la religión es «la religión de un poeta, y no la de un hombre de piedad ortodoxa, ni la de un teólogo» ${ }^{10}$. La religión, en Tagore, lejos de consistir en un esquema cerrado y artificial que ha de aceptarse sin más, constituye un anhelo espiritual de conexión con el mundo «creo en un mundo espiritual, no separado de este mundo, sino como su verdad más íntima. Con cada aliento que expulsamos debemos sentir siempre esa verdad: que vivimos en Dios. Nacidos en este gran mundo, llenos del misterio de su infinito, no podemos aceptar nuestra existencia como un estallido de casualidad momentáneo, derivando en la corriente de la materia hacia una nada eterna» ${ }^{11}$.

Esta concepción de la religión le lleva necesariamente a entender que lo verdaderamente importante de las religiones es aquello que tienen en común y no lo que separa unas de otras «aquello que más valoro en mi religión o mi aspiración es lo que deseo corroborar, en su unidad fundamental, en otras grandes religiones, o en las esperanzas expresadas en la historia de otros pueblos. Todo gran movimiento de pensamiento y de conducta en cualquier parte del mundo puede tener algo único en su expresión, pero la verdad subyacente a cualquiera de ellos nunca tiene la rimbombante ordinariez de la novedad absoluta. El gran Ganges no debe dudar en declarar su similitud esencial con el Nilo de Egipto o con el Yangtse-Kiang de China» ${ }^{12}$.

8 Ibíd., p. 2.

9 Tagore, R. (1931), The Religion of Man, Being the Hibbert Lectures for 1930, London: George Allen and Unwin. (Tagore, R. (2002) La religión del hombre, Barcelona: RBA, Traducción de Rafael Cansinos Assens).

10 Tagore, Rabindranath (2010) Palabra por palabra (Textos autobiográficos), p. 321.

11 Ibíd., p. 323.

12 Ibíd., p. 326. 


\section{El universalismo}

Si Tagore aportó una visión integradora en el ámbito de lo religioso, también manifestó esta misma tendencia en otros aspectos. Con 17 años es enviado a Inglaterra para cursar la carrera de Derecho y perfeccionar el inglés, durante los dos años que permanece en Inglaterra se interesó más por la literatura y la cultura inglesa que por las leyes. Sin terminar sus estudios, regresó a la India con un bagaje rico en experiencias personales y con un profundo conocimiento de la literatura y la mentalidad occidentales que, unido a sus raíces culturales, le permitió ir amasando la base de ese sincretismo intelectual y espiritual que habría de animar toda su obra literaria.

Por encima de las evidentes diferencias existentes entre Oriente y Occidente, Tagore, supo situar los valores permanentes de la verdad y de la belleza. El participar de distintas culturas le hizo entender y tratar de complementar sensibilidades diferentes pero no antagónicas.

Tagore, trato de apreciar, en un primer momento, aquellos aspectos positivos que trajo consigo la dominación inglesa a la India y hacerlos compatibles con la propia idiosincrasia del pueblo indio. Veía necesario la modernización de la India para que saliera de su ostracismo, de su pobreza secular, y para ello, en ocasiones, denunció una actitud que amparada en la tradición constituía un obstáculo insalvable «si nos mantenemos aparte en nuestra «pureza», transmitiendo a las generaciones que nos sucedan este orgulloso aislamiento, si reservamos nuestra religión y nuestras costumbres sociales exclusivamente para nosotros, si prohibimos la entrada en nuestros templos a los extranjeros y guardamos bajo llave nuestras antiguas tradiciones, no hacemos sino proclamar ante el mundo que hemos sido condenados a muerte por el tribunal de la humanidad y esperamos la ejecución de la sentencia encerrados en celdas que nosotros mismos hemos construido» ${ }^{13}$.

Pero, Tagore, con el paso del tiempo se desencantaría de esa pretendida «influencia positiva» que podría aportar el dominio inglés sobre la India, volviéndose crítico al contemplar como en definitiva prevalecían una serie de intereses espurios sobre una pretendida liberalidad e igualdad que se veían comprometidas por la propia naturaleza de la empresa colonial «...me empecé a dar cuenta de cuán fácilmente aquellos que aceptan las verdades más elevadas de la civilización dejan de tenerlas presentes cuando entran en juego asuntos de interés nacional» ${ }^{14}$.

Orgulloso de su patria, Tagore, siempre abominó de cualquier tipo de patriotismo o de nacionalismo. Su noción de patria era más de carácter espiritual que propiamente material «Amo la India no porque cultive la idolatría de la geografía, no porque haya tenido la oportunidad de haber nacido en su suelo, sino porque ella ha salvado a lo largo de tumultuosa épocas las palabras vivas que han salido de la conciencia iluminada de sus grandes hijos: Satyam, Jnanam, Anantam, Brahama, Brahma es la verdad, Brahma es la sabiduría, Brahma es infinito; Santam, Sivam, Advaitam, la paz se halla en Brahma, la bondad está en Brahma y la unidad de todos los seres» ${ }^{15}$.

13 Tagore, Rabindranath (2004), «Oriente y Occidente», en Oriente y Occidente en la India de los siglos XX y XXI, Barcelona: Casa Asia, pp. 411 y 412.

14 Tagore, (14) Rabindranath (2004), «Crisis de la civilización» en Oriente y Occidente en la India de los siglos $X X$ y $X X I$, p. 474.

15 Tagore, Rabindranath (2010), Palabra por palabra» (Textos autobiográficos, p. 342. 
Aunque, Tagore, nunca renunció al entendimiento entre Oriente y Occidente, pudo comprobar de propia mano y pese a haber recibido una educación occidentalizada, las dificultades importantes que supone el tratar de conciliar formas tan diferentes de entender la vida. «Las enseñanzas y el ejemplo de Occidente están en absoluta contradicción con la tarea encomendada a la India. En Occidente la maquinaria nacional del comercio y de la política produce pacas de humanidad pulcramente comprimidas que tienen su utilidad y poseen gran valor en el mercado, pero las sujetan aros de hierro y se las etiqueta y clasifica con esmero y precisión científicos. Evidentemente, Dios hizo al hombre para que fuera humano, pero este producto moderno, con su impronta de gran industria, tiene un corte tan perfecto que al Creador la resultará difícil reconocerlo como el fruto de una criatura hecha a su divina imagen» ${ }^{16}$.

Cuestionando, en gran medida, la vigencia actual de la distinción entre Oriente y Occidente como dos categorías opuestas, Menene Gras Balaguer, considera que «Oriente y Occidente son palabras que se elevan con facilidad a conceptos, por el uso que se ha hecho de ellas, para designar lo que no es igual en una amplia cartografía que se extiende de este a oeste y al revés» ${ }^{17}$.

«Los encuentros y desencuentros entre Oriente y Occidente» ${ }^{18}$ es un tema presente en muchos planteamientos llevados a cabo por especialistas en la materia, y que pese a ser una cuestión compleja y ampliamente debatida, no deja de suscitar entusiasmos, si cabe cada vez en mayor medida, debido al interés que de un tiempo a esta parte provoca todo lo relacionado con la sabiduría oriental. La manera de entender esta relación ha sido diversa, desde el mundo occidental en ocasiones se ha pecado de falta de comprensión, como señala, María Teresa Román, «es lamentable la miopía con que el mundo occidental ha mirado -y, ha obviado- todas las culturas que le eran ajenas y, que ha pretendido filtrar y discernir según sus propios e insuficientes cánones de la razón, su razón» ${ }^{19}$.

Pero, frente al pesimismo de algunos, como Kipling, que auguraba el desencuentro permanente entre Oriente y Occidente, Tagore, siempre apostó en su vida y en su obra por lograr un sincretismo entre culturas, llegando a afirmar que «...todos los conflictos actuales se deben a esta falta de contacto entre Oriente y Occidente» ${ }^{20}$. De ejercer una autocrítica hacia el pueblo indio, al que acusaba de mantener una actitud aislacionista y no saber aprovechar las ventajas del contacto con los ingleses, con la salvedad de ciertas individualidades entre ellas, Ram Mohan Roy o Vivekananda; pasó a mantener una actitud crítica frente a Inglaterra como consecuencia de la represión ejercida hacia el movimiento independentista. Hasta el punto de renunciar en 1919 al título de caballero que le fue concedido en 1915 por el gobierno británico, como protesta por la masacre de Amritsar.

En la lucha por el independentismo, buscó un camino alternativo, oponiéndose a la política mantenida por el Congreso consistente en pedir favores al Gobierno. Seducido, en un primer momento por el movimiento del renacimiento hindú, formó parte del movimiento

16 Tagore, R. (2012), Nacionalismo, Madrid: Taurus, pp. 45 y 46.

17 Gras Balaguer, Menene (2004), Oriente y Occidente. Barcelona: Casa Asia, p. 57.

18 «Encuentros y desencuentros entre Oriente y Occidente» es el primer capítulo del libro Enseñanzas espirituales de la India, de María Teresa Román López (2001), pp. 19-69.

19 Ibid., p. 20.

20 Tagore, R. (2004), «Oriente y Occidente», cit., p. 417. 
swadeschi ${ }^{21}$, contribuyendo activamente con diversas acciones en favor de la independencia de la India, pero decepcionado por el empleo de la violencia comunitaria se apartó de la ideología del renacimiento hindú para siempre. Convencido de que en su país el cambio social era mucho más urgente que la libertad política acusó a los líderes políticos por haber desplazado su foco de atención. «El verdadero problema de la India no es político sino social. Es un mal que no afecta sólo a la India, sino a todas las naciones. No creo que exista un interés exclusivamente político, pero los ideales de Occidente se han regido por la política y en la India intentamos imitarlos» 22 .

Frente al sentimiento nacionalista reacciona enérgicamente oponiendo su talante humanista y universalista «en realidad, la India nunca ha asimilado el nacionalismo. Aunque a mí se me enseñó en la infancia que el culto a la nación era casi mejor que reverenciar a Dios y a la humanidad, creo haber superado esas enseñanzas. Estoy convencido de que mis compatriotas recobrarán la India luchando contra una educación que les enseña que un país es más importante que los ideales de la humanidad» ${ }^{23}$.

Rabindranath fue contemporáneo de otro gran líder espiritual, Gandhi, y aunque sentía la mayor admiración por Mahatma Gandhi como persona y dirigente político, se mostraba también muy escéptico acerca del nacionalismo de Gandhi y de sus instintos conservadores tocantes a las tradiciones del país. Compartiendo un mismo objetivo diferían en cuanto a los medios para alcanzarlo. Las diferencias entre ambos no constituyeron sin embargo un obstáculo para la existencia de una amistad y admiración mutuas que tuvieron ocasión de profesarse en numerosos encuentros. «Me resulta extraordinariamente desagradable estar en desacuerdo con Mahatma Gandhi en relación con cualquier asunto de principios o de método. No se trata de que, desde ningún punto de vista, exista nada equivocado en ese hecho, pero se me encoge el corazón al pensarlo. Porque, ¿qué mayor alegría podría haber que unir las manos en el trabajo con alguien a quien se ama y se reverencia?» ${ }^{24}$.

Frente al nacionalismo militante de Gandhi se encuentra el universalismo integrador de Tagore; frente, en ocasiones, el arcaísmo de Gandhi, se alza la fe de Tagore en el progreso. Ambos constituyen dos pilares fundamentales de la historia reciente de la India y de la búsqueda comprometida por su liberación.

\section{Santiniketan}

Uno de los aspectos quizás menos divulgados de Tagore es su labor como educador, constituyendo, sin embargo, un aspecto central en su vida y en su obra. A partir de la experiencia educativa, frustrante, que tuvo durante su infancia y que le llevó a abandonar tempranamente las instituciones educativas, siendo educado prácticamente por sus propios hermanos, sintió que el tema de la educación era fundamental para su país. «Desde mi punto de vista, la impresionante torre de miseria que hoy descansa sobre el corazón de la India tiene su

21 El movimiento swadeschi, dentro de la lucha por la independencia frente al Imperio Británico, constituyó una estrategia económica que buscaba la autosuficiencia económica mediante una serie de medidas como el boicot a los productos británicos, así como el restablecimiento de la economía doméstica y sus técnicas de producción.

22 Tagore, R. Nacionalismo, cit., p. 77.

23 Ibíd., p. 84.

24 Tagore, R. Palabra por palabra (Textos autobiográficos), cit., p. 247. 
causa única en la falta de educación. Las divisiones de castas, los conflictos religiosos, la aversión por el trabajo, las condiciones económicas precarias, todo se centra en este único factor» 25 .

Tagore, al encargarse de la administración de las propiedades que su familia tenía en el campo, se percató de las posibilidades que ofrecían la educación y la cooperación para transformar la vida rural. Empezó organizando cooperativas, escuelas y hospitales en las aldeas de su propiedad, y trató de mejorar las técnicas de cultivo. Tagore denominó a este período su Sadhana ${ }^{26}$, es decir, camino, reflexión, austeridad y autoeducación para llevar una vida social activa.

En el verano de 1901 se trasladó con su familia al ashram ${ }^{27}$ que su padre poseía en Santiniketan y el 22 de diciembre del mismo año inauguró una escuela que, en cierta manera, constituiría una respuesta al nacionalismo constructivo. Para Tagore un nacionalismo estrecho conducía necesariamente a los hombres y a los países por las vías del conflicto, y era necesaria una institución que fomentase la unidad de las culturas. Para él Santiniketan («La morada de la paz») era ésta institución.

Aunque, Tagore, escribió mucho sobre el tema educativo, no lo hizo de manera sistemática, de tal manera que sus reflexiones sobre este aspecto están dispersas en diversos textos, ensayos, artículos de prensa, conferencias y cartas particulares, escritas a lo largo de los años. Para Tagore, como ya hemos señalado anteriormente, la falta de educación constituía el principal obstáculo para el progreso de la India y el origen de todos sus males. El sistema educativo precolonial era muy deficiente, pero el sistema colonial también adolecía de grandes defectos, tanto en cuanto a sus contenidos, como en otros aspectos, como en el hecho de impartirse en lengua inglesa con las dificultades que eso conllevaba para la población. Además producía una segregación entre aquella población que recibía educación y que era la clase rica, educada y anglófona que vivía en las ciudades y aquella otra población que predominantemente vivía en el campo y que no tenía medios materiales ni acceso a la cultura.

En un primer momento, Tagore, se inspiró para sus propósitos educativos en las antiguas escuelas forestales de la India, ya que se trata de un tipo de escuela característico del sistema de educación indio, basado principalmente en los tres pilares fundamentales de la cultura nacional, a saber, la Advaita (no dualidad) por lo que se refiere al conocimiento, la amistad hacia todos en la esfera de los sentimientos, y el cumplimiento del deber sin preocuparse de las consecuencias, en lo relativo a la acción. La escuela forestal aunaba la educación con la Sadhana (dominio de los sentidos y de la propia vida). Pero Tagore actualizó esta forma de enseñanza, incluyendo otras disciplinas, entre ellas las científicas.

El método educativo desarrollado en Santiniketan era peculiar y, en muchos casos, innovador, tratando de hacer más atractivas y amenas las clases que, siempre que era posible, se impartían al aire libre. Para Tagore tan importante como la educación del intelecto y de los sentidos, era la educación de los sentimientos. En gran medida valoraba la

25 Tagore, citado por Amartya Sen en «Tagore y su India», Oriente y Occidente en la India de los siglos XX y XXI, cit., p. 199.

26 Término sánscrito que significa «práctica espiritual».

27 Comunidad espiritual, propia del hinduismo, en la que convive un guía espiritual junto a sus discípulos. 
dimensión estética considerando que «...nuestro ego se expresa en el movimiento visible de las actividades; pero nuestro subconsciente, residencia del alma, necesita también medios apropiados de expresión, tales como la poesía, la música y las artes. A través de éstas se manifiesta la plenitud de la personalidad humana» ${ }^{28}$.

Así mismo, Tagore, insistió en la necesidad de impartir las clases en la lengua materna, ya que la utilización del inglés generaba muchos problemas y dificultaba una educación dirigida a todas las clases sociales.

El universalismo de Tagore encontró su cauce natural de propagación a través de una educación cuyo objetivo primordial era el desarrollo integral de la personalidad del individuo, mediante la interacción armoniosa y la unión del espíritu con su entorno. De acuerdo con esta idea, la escuela de Santiniketan recibió un nuevo nombre y adquirió al mismo tiempo una nueva categoría, la de Universidad Mundial. Con el nombre Vishva Bharati se inauguró solemnemente en diciembre de 1918.

El propósito de Tagore era la creación de un centro que respondiera a las necesidades culturales del país, era consciente de que la India, en este aspecto, tampoco podía vivir de prestado. «He aquí por qué la educación europea no puede ser para la India otra cosa que una enseñanza escolar y nunca una cultura. La caja de cerillas es útil para muchos usos, pero no puede suplir la luz de la aurora, donde la gracia y la utilidad se alían en el misterio sutil de la vida. Y ésta es la razón por la cual el alma interna de la India nos exhorta a establecer en nuestro país centros donde todos sus valores intelectuales se reúnan con un espíritu de creación y donde todos los recursos de la sabiduría y del pensamiento de Oriente y Occidente coincidan en perfecta armonía» 29 .

\section{El pensamiento poético}

Después de insistir sobre la versatilidad de Rabindranath Tagore, proyectada en una obra plural que mana de su profunda espiritualidad, es conveniente tomar en consideración la opinión que el propio Tagore tenía acerca de sí mismo. En sus escritos autobiográficos, Tagore, expresa el siguiente veredicto «No es fácil conocerse a sí mismo. Es difícil organizar las diversas experiencias de la vida en un todo unificado. Si Dios no me hubiese dado una larga vida, si él no me hubiese permitido llegar a los setenta años, apenas habría conseguido tener una imagen clara de mí mismo. He intentado darle sentido a mi vida en diferentes ocasiones a través de diversas actividades y experiencias. Lo único que he conseguido concluir sobre mí mismo es que sólo soy un poeta, nada más, por muchas otras cosas que haya hecho a lo largo de mi vida» ${ }^{30}$. La condición de poeta, por lo tanto, está presente en toda la vida y la obra de Tagore, constituye el río natural por el que discurre su pensamiento.

$\mathrm{Al}$ emplear los términos pensamiento poético somos conscientes de las dificultades de aunar dos palabras que, en principio, no parecen tener un claro parentesco e incluso que pueden parecer contradictorias. «...el intelecto (la vigilia) piensa por medio de abstrac-

28 Tagore, R. «Centro de la cultura India», Oriente y Occidente en la India de los siglos XX y XXI, cit., p. 467.

29 Ibíd., p. 464.

30 Tagore, R. «Atmaparichay (Conocerse a sí mismo)», en Palabra por palabra (Textos autobiográficos), cit., p. 13. 
ciones, la poesía (el sueño), por medio de imágenes, de mitos o de fábulas» ${ }^{31}$. Si esto es así, con carácter general, en Occidente la separación entre «concepto y metáfora» ha sido más evidente desde la ya célebre condena de Platón a los poetas. Se ha considerado que lo filosófico se debe reservar exclusivamente para lo conceptual, para el razonamiento lógicodiscursivo, y se entiende que fuera de Occidente este tipo de pensamiento o no existe o no se ha desarrollado en la medida en que lo ha hecho en Occidente.

Este carácter del pensamiento occidental le ha llevado, consecuentemente, a una pretensión del conocimiento verdadero, deslindando lo verdadero de lo falso; pretensión que no existe en la India donde no se ha dado esta interpretación restrictiva y excluyente de la verdad, antes al contrario se ha procurado una visión más amplia e integradora, para Helmuth von Glasenapp, «Esta posición dinámica, frente al concepto de verdad, les procuró a los filósofos indios desde muy pronto el conocimiento de que todas las tentativas de explicar el mundo sólo pueden tener un valor provisorio y simbólico» ${ }^{32}$.

Tagore nos presenta la realidad, su lenguaje poético nos pone en contacto con la realidad. Sus poemas no constituyen una representación de lo real, nos ofrecen el mundo.

Como señala, acertadamente, Raimon Panikkar, «Toda palabra es palabra porque tiene un sentido, no porque signifique un concepto. El concepto es el significado de un pensamiento vehiculado por una palabra. Pero ésta tiene además un sentido que no se identifica con el concepto. El sentido es un sendero, una sensibilidad, una dirección, una intención, mucho más amplia que la intencionalidad conceptual» ${ }^{33}$.

Todo el «pensamiento poético» de Tagore se nos muestra como expresión de esa sensibilidad, de esa interioridad liberada. Incluyendo dentro del «pensamiento poético» otras formas de expresión artística que cultivó también como fueron la música o la pintura y que responden también a esa misma inquietud creadora. En definitiva, en este aspecto también, Tagore, es un claro exponente de sus raíces culturales. Como sostiene el filósofo hindú Sarvepalli Radhakrishnan «En general se puede decir que el signo dominante del pensamiento oriental es su insistencia en la intuición creadora mientras que las filosofías de Occidente se caracterizan por su extraordinario apego a la inteligencia crítica» ${ }^{34}$.

\section{Conclusiones}

Todos los aspectos en que se vertebra la obra de Rabindranath Tagore responden en última instancia a esa necesidad de comprensión del universo, a esa mística que lejos de perderse en la pasividad autocomplaciente, se dirige a la transformación del individuo y de la sociedad. «La revolución en la sociedad debe empezar por la transformación interior, psicológica, del individuo» ${ }^{35}$.

31 Borges, Jorge Luis (1981), La cifra. Madrid: Alianza Editorial, p. 1.

32 Glasenapp, Helmuth von (2007), La filosofía de la India, Madrid: Biblioteca Nueva, p. 372.

33 Panikkar, Raimon (1997), La experiencia filosófica de la India, Madrid: Trotta, p. 71.

34 Radhakrishnan, Sarvepalli (1971), «La religión en Oriente y en Occidente», en VV.AA., Las grandes religiones enjuician al cristianismo, Bilbao: Mensajero, p. 35.

35 Krishnamurti (1996), La libertad primera y última, Barcelona: Kairós, p. 37. 
Dentro de lo que constituye «el pensamiento de la India» reciente, Tagore, representa mediante su vida y su obra la actitud del artista y del intelectual moderno que sin renunciar nunca a sus orígenes es capaz de abrirse a nuevos horizontes. Comprometido con sus creencias y comprometido con su tierra y su tiempo, es hoy uno de los referentes para entender que el diálogo entre culturas es algo necesario.

En un mundo como el actual, tan complejo, es de valorar un pensamiento libre de prejuicios, riguroso en sus formulaciones pero al mismo tiempo lo suficientemente flexible para abarcar la diversidad. Sensible a los distintos modos de vivir y de sentir, con una visión integradora, abierta, comprensiva de la realidad en su pluralidad, en su diferencia múltiple y variopinta. La aportación universalista de Tagore constituye en nuestros días un valor incuestionable. Solamente desde un posicionamiento de estas características podremos acceder hacia un conocimiento pleno y no mutilado por pretensiones exclusivistas, solamente así podremos superar el «provincianismo cultural» ${ }^{36}$.

\section{Referencias}

Borges, J. L. (1981), La cifra. Madrid: Alianza Editorial.

Eliade, M. (1973), Mito y realidad, Madrid: Guadarrama.

Glasenapp, H. von (2007), La filosofía de la India, Madrid: Biblioteca Nueva.

Gras Balaguer, M. (2004), Oriente y Occidente. Barcelona: Casa Asia.

Krishnamurti (1996), La libertad primera y última, Barcelona: Kairós.

Panikkar, R. (1997), La experiencia filosófica de la India, Madrid: Trotta.

Radhakrishnan, S. (1971), «La religión en Oriente y en Occidente», en VV.AA., Las grandes religiones enjuician al cristianismo, Bilbao: Mensajero.

Román López, M. T. (2001), Enseñanzas espirituales de la India, Madrid: Oberón.

Ruiz Calderón, J. (2008), Breve historia del hinduismo, Madrid: Biblioteca Nueva.

Sen, A. (2004), «Tagore y su India», Oriente y Occidente en la India de los siglos XX y $X X I$, Barcelona: Casa Asia.

Tagore, R. (1931), The Religion of Man, Being the Hibbert Lectures for 1930, London: George Allen and Unwin. (Tagore, R. (2002) La religión del hombre, Barcelona: RBA, Traducción de Rafael Cansinos Assens).

Tagore, R. (1999), La morada de la paz, Barcelona: Ediciones Oniro.

Tagore, R. (2004), «Oriente y Occidente», en Oriente y Occidente en la India de los siglos $X X$ y XXI, Barcelona: Casa Asia.

Tagore, R. (2010), Palabra por palabra (Textos autobiográficos), Barcelona: La otra orilla. Tagore, R. (2012), Nacionalismo, Madrid: Taurus.

36 «Provincianismo cultural», expresión utilizada por Mircea Eliade en su libro Mito y realidad, Guadarrama, Madrid, 1973, p. 153. 
